\title{
COMPARISON OF AUTOGENOUS PERIOSTEAL PEDICAL GRAFT AS A BARRIER AND BIORESORBABLE COLLAGEN MEMBRANE IN MANAGEMENT OF PERIODONTAL INTRABONY DEFECTS: A RANDOMIZED CONTROLLED CLINICAL TRIAL
}

\author{
Ghallab NA*, El Battawy WA**, Darhous $\mathrm{M}^{*}$ and Hamdy RM***
}

\begin{abstract}
Introduction: The autogenous periosteal pedicle graft (PPG) has been viewed as having regenerative potential and provides adequate blood supply rich in growth factors. It also provides a rigid barrier maintaining the patency of the periodontal intrabony defect space for regenerative cell repopulation. Thus, PPG might be an alternative to currently available barrier membranes used for guided tissue regeneration (GTR). So, the aim of this study was to evaluate the clinical and radiographic outcomes of autogenous PPG as a barrier compared to bioresorbable collagen membrane (CM) for treating periodontal intra-bony defects.
\end{abstract}

Materials and methods: Twenty chronic periodontitis patients having matched contralateral periodontal intrabony defects participated in this randomized controlled clinical trial. Using splitmouth design, defects were randomly treated with either autogenous PPG or bioresorbable CM (Bioteck ${ }^{\circledR}$, Arcugnano VI, Italy). Clinical outcomes included; plaque index (PI), gingival index (GI), probing pocket depth (PPD) and clinical attachment level (CAL). Digital periapical radiographs and linear measurements were used to calculate the radiographic outcomes; bone defect area (BDA). Measurements were taken at the time of surgery (baseline) and 6-months postoperatively. Statistical analysis was conducted using Wilcoxon's-Signed-Rank test.

Results: At 6 months both treatments resulted in statistically significant improvement in all clinical and radiographic outcomes compared with baseline $(\mathrm{P}<0.0001)$. In the PPG group, the $\mathrm{PPD}($ mean $\pm \mathrm{SD}$ ) was reduced from $6.92 \pm 0.76 \mathrm{~mm}$ to $3.17 \pm 0.65 \mathrm{~mm}$, the CAL (mean $\pm \mathrm{SD}$ ) was improved from $6.42 \pm 0.56 \mathrm{~mm}$ to $3.52 \pm 0.44 \mathrm{~mm}$, the reduction in BDA (mean $\pm \mathrm{SD}$ ) was $3.94 \pm 4.09$ $\mathrm{mm}^{2}$ and the percentage of reduction in BDA (mean $\pm \mathrm{SD}$ ) was $39.47 \pm 20.77 \%$. In the CM group, the PPD $($ mean \pm SD) was reduced from $6.82 \pm 1.1 \mathrm{~mm}$ to $3.15 \pm 0.67 \mathrm{~mm}$, the CAL (mean $\pm \mathrm{SD}$ ) was improved from $6.15 \pm 0.98 \mathrm{~mm}$ to $3.6 \pm 0.57 \mathrm{~mm}$, the reduction in BDA (mean $\pm \mathrm{SD}$ ) was $3.54 \pm 3.44$ $\mathrm{mm}^{2}$ and the percentage of reduction in BDA $($ mean $\pm \mathrm{SD})$ was $34.55 \pm 26.88 \%$. Differences between groups were not statistically significant $(\mathrm{P}>0.05)$.

Conclusion: Within the limitations of this study, it can be concluded that both the autogenous PPG and the bioresorbable CM improved clinical and radiographic outcomes and were effective GTR membranes in management of intra-bony defects.

* Professor of Oral Medicine and Periodontology, Faculty of Dentistry, Cairo University

** Lecturer of Oral Medicine and Periodontology, Faculty of Dentistry, Cairo University.

*** Assistant professor of Oral and Maxillofacial Radiology, faculty of Dentistry, Cairo University. 


\section{INTRODUCTION}

Tissues regeneration is the optimal goal of periodontal therapy when a significant amount of periodontal attachment is lost. Combined therapy including root debridement and plaque control has showed efficient improvement in subsiding inflammation and stopping further progression of periodontitis ${ }^{(1,2)}$ where healing basically results in the formation of a long junctional epithelium ${ }^{(3)}$ and alveolar bone remodeling ${ }^{(4)}$. In addition, surgical debridement by itself does not promote significant regeneration of new connective tissue attachment $^{(5)}$, and occasionally, modest bone regeneration may occur in selected sites ${ }^{(3,6)}$.

According to The American Academy of Periodontology (2001) ${ }^{(7)}$, regeneration has been described as the reproduction or reconstitution of a lost or injured part. Therefore, histologically, periodontal regeneration was defined as regeneration of supporting tissues of the tooth including periodontal ligament, alveolar bone and cementum over a previously diseased root surface.

Guided Tissue Regeneration (GTR) has been introduced into clinical dental practice over 30 years ago, when Melcher (1976) ${ }^{(8)}$ declared that the nature of the attachment which will form on the root surface is determined by the cells which will repopulate after periodontal surgery. GTR supported with barrier membranes has been effective in preventing the migration of epithelial and gingival connective tissue cells into the blood clot that forms on the root surface after instrumentation. Barrier membranes are placed to cover the area intended for tissue regenerative process as they are properly shaped and positioned to preserve the space around the bony defect and the root surface so that periodontal ligament and bone cells, which are expected to colonize the blood clot, can express their potential for cementum, periodontal ligament and alveolar bone regeneration ${ }^{(9,10)}$.

Accordingly, the literature suggested that when treating two- or three-wall osseous defects, as well as Class II furcations, clinical results achieved using GTR were more predictable and durable than simple access flap surgery ${ }^{(11,12)}$.

In 2008, a novel marginal periosteal pedicle (MPP) graft was introduced by Gamal and Mailhot $^{(13)}$ as a biologic GTR membrane as an attempt to manage deep angular two- and three-wall infrabony periodontal defects. They reported that clinical and radiographic parameters of deep intrabony defects were significantly improved after the use of vascularized MPP graft as a barrier membrane. Moreover, they proved that MPP was superior to open flap debridement (OFD) alone.

Moreover, MPP graft was examined clinically and histologically as a biologic guided tissue membrane. Not only clinical improvement was observed but also, histologic evaluation of test samples revealed coarse-fibered woven bone filling the defect nine months following therapy in three of the 10 examined newly formed tissue samples and a homogenous layer of cementum-like tissue deposition was detected in apical root notches of such samples ${ }^{(14)}$.

Therefore, the periosteal grafts, a complex biologic structure rich in osteoprogenitor cells and more, has been viewed as having regenerative power to stimulate new bone reformation because they stimulate osteogenic factors. Periosteal grafts also provided the wound area with additional osteoprogenitor cells, which may compensate for the deficiency of cells available in the periodontal defect. In addition, the periosteum could provide a barrier rigid enough barrier preserve and shelter the space of the osseous defect for the new cell repopulation to migrate in and regenerate lost periodontal and osseous tissues and could be a good alternative to the currently available GTR materials ${ }^{(15)}$.

Collagen membranes (CM) utilized for GTR have been widely used for many reasons. First, their biocompatibility since collagen is a natural tissue barrier that is tissue compatible with the 
host. Second, their absorbable nature which provide a frame for tissue regeneration in line with expanding the thickness of the gingiva by tissue augmentation. Third, their chemotactic makeup which stimulate the native cell migration, namely the neutrophils and fibroblasts, followed by cell attachment, subsequently promote primary flap healing which eventually reduce the likelihood of membrane exposure and potential wound / membrane contamination. Fourth, collagen promote hemostasis which encourages blood clot formation and hence wound integrity. Fifth, they are semipermeable which allow transudative exchange of gas and nutrient thus encourage better flap healing. All these properties represent the essential factors for optimal flap healing: primary wound closure, wound/ clot integrity, space preservation, delay apical migration of epithelial components and regeneration of connective tissue attachment ${ }^{(16)}$.

Therefore, the present study was aimed to evaluate the clinical and radiographic outcomes of autogenous periosteal pedicle graft (PPG) compared to bioresorbable $\mathrm{CM}$ for treating periodontal intrabony defects.

\section{MATERIALS AND METHODS}

\section{Study design}

This study was designed as a parallel, randomized, controlled clinical trial to compare the clinical and radiographic outcomes of autogenous PPG with bioresorbable CM as GTR techniques for management of periodontal intrabony defects. The study protocol was registered in ClinicalTrials.gov (ID: NCT02248103) and approved by The Research Ethics committee, Faculty of Dentistry, Cairo University (June 2014). This study was reported according to CONSORT guidelines, 2012 (Moher et al. 2012) ${ }^{(17)}$.

\section{Study population}

Twenty patients (both males and females) with an age ranging from 35 to 50 years old with chronic periodontitis participated in this prospective randomized controlled clinical trial. Selection of patients was from the Outpatient clinic, Department of oral Medicine and Periodontology, Faculty of Dentistry, Cairo University.

The selection criteria included the following: 1) Individuals were healthy and free from systemic disease that may contraindicate periodontal surgery and influence the outcome of the therapy, according to the detailed questionnaire of the dental modification of the Cornell medical index (18); 2) Patients selected did not receive antibiotics or any medication for at least 6 months prior to this study; 3) Patients selected did not receive professional scaling and root planning (SRP) within the last 12 months; 4) Patients were willing and able to return for multiple follow up visits; 5) Patients were diagnosed with advanced chronic periodontitis. Each patient exhibited at least one site of clinical attachment level (CAL) $\geq 5 \mathrm{~mm}$ in 2 quadrants; 6) Based on clinical examination, 20 patients were selected with two sites at least with probing pocket depth $(\mathrm{PPD}) \geq 6 \mathrm{~mm}$ and $\mathrm{CAL} \geq 5 \mathrm{~mm}$. Bone loss was confirmed by radiographic evidence of 2- or 3 -wall intrabony defects, with depth that ranged from 3 to $6 \mathrm{~mm}$ and detected in the screening conventional intraoral periapical radiographs. The labial/buccal surfaces of the teeth adjacent to the interproximal defect should be free of marginal loss of bone or any severe recession. At least 4 to $5 \mathrm{~mm}$ band of keratinized gingiva should be available to allow for manipulation of the periosteum. Final judge whether the osseous defects were 2- or 3- wall defect was assessed at the time of surgery.

The exclusion criteria included the following: 1) individuals with 1-wall defects, 2) individuals with any harmful habits, as smoking or tobacco chewing; 3) patients with systemic diseases that might contraindicate for periodontal surgery and 4) pregnant or lactating females. A comprehensive examination of the dental and medical history was 
completed by all the participants, then the study purpose was explained in detail with all the benefits and risks associated. The patients were asked to fill a signed informed consent.

\section{Randomization}

An investigator (GN) generated a random allocation sequence using computer program (www. random.org). Allocation concealment was achieved by placing this sequence in sequentially-numbered, opaque, sealed envelopes which included the randomization code for each patient that was not broken until follow-up was concluded. Allocation was implemented by an investigator (GN) who was neither directly involved in the examination nor the treatment procedures. After pretreatment phase, eligible participants who agreed to complete the study were randomly assigned into two equal groups with a 1:1 allocation ratio to receive either OFD with bioresorbable CM as a GTR barrier or OFD with autogenous PPG defect coverage as an autogenous membrane for GTR.

\section{Blinding}

In this clinical trial; participants, outcome assessor and statistician were blinded to the type intervention being allocated.

\section{Pretreatment phase}

The participants received a full diagnostic workup including a full mouth probing. Participants were given oral hygiene instructions. Full mouth meticulous SRP was performed, and $0.12 \%$ chlorhexidine digluconate mouth rinse was prescribed for 2 weeks. Occlusal adjustment was performed for relieving any traumatic occlusion. The patients were reevaluated four weeks after the pretreatment phase for recording the clinical and radiographic outcomes (baseline data) followed immediately by the surgical phase.

\section{Surgical phase}

Intrabony defects were assessed at the time of surgery and alternate sites in each participant were randomized in a split mouth design as PPG group and $\mathrm{CM}$ group. In the $\mathrm{CM}$ group, OFD was performed and a bioresorbable CM (Bioteck* commercial barrier) was adapted on the intrabony defect to act as a GTR membrane. In the PPG group, OFD was performed and autogenous PPG was adapted for defect coverage as an autogenous membrane for GTR as explained in detail by Gamal and Mailhot in $2008^{(13)}$. Intrasulcular incisions were performed facially and lingually extending one or two teeth mesial or distal to the intrabony defect to preserve the keratinized tissue as much as possible. The selection of the donor site was based on the width of the available attached gingiva within the adjacent teeth, where the tooth with wider attached gingiva was selected. Subsequently, the facial periosteum was uncovered using a facial releasing vertical incision that extended to the alveolar mucosa for better donor graft tissue accessibility. Flap reflection was performed by facial partialthickness and a supra-periosteal manner to an extent that permitted free movement of 3 to $4 \mathrm{~mm}$ strip of pedicle periosteal membrane. Sharp dissection of the flap was performed as close as possible to the periosteum in apico-coronal movements using surgical blade \#15 so as to provide a soft tissue flap with approximately 2- to $2.5 \mathrm{~mm}$ wall with uniform thickness. Careful extension of the flap under tension was done with the apical extension of the incision, so as not to perforate the base of the flap accidentally with the blade and also for maximum preservation of the interproximal soft tissue. However, the lingual flap was raised in fullthickness mucoperiosteal manner to a 2 to $3 \mathrm{~mm}$ depth to allow better debridement and adaptation of the pedicle periosteal membrane. After partial-

* Bioteck S.P.A.: Biocollagen made of Achilles' tendon collagen. Via Giovanni Agnelli, 3. 10020 Riva Presso Chieri (TO)- Italy. 
thickness elevation of the soft tissue flap, a strip of the marginal periosteal membrane was taken from the periosteum facially just adjacent to the intrabony defect by performing a vertical incision that started from the alveolar crest extending $4 \mathrm{~mm}$ apically plus another horizontal incision running parallel to the gingival margin. A periosteal elevator was used to harvest the periosteum under tension with the lateral extension of the separation, while keeping the base attached to be used as a biologic pedicle barrier membrane. The granulation tissue in the intrabony defect was debrided and the root was planned till obtaining a healthy sound bone surface, with copious irrigation with sterile saline. Then the pedicle periosteal membrane harvested was carefully rotated just to cover the interproximal intrabony defect without suturing because the adherence of the flap to the bony surfaces was sufficient. Finally, after removal of any tissue tags or remnants in the pocket lining, the soft tissue flap was freed from any tension, adapted and repositioned to cover the entire pedicle periosteal membrane and approximated to its original position with interproximal and sling sutures.

Postoperatively all patients were placed on antibiotic regimen (Amoxicillin* $500 \mathrm{mg}$ t.d.s and metronidazole $^{* *} 250 \mathrm{mg}$ t.d.s) for 1 week after surgery to prevent post-surgical infection and were instructed to rinse with $0.12 \%$ chlorhexidine twice daily for a 1 minute duration to help in plaque control at the early healing phase. Oral analgesics were also prescribed (Brufen ${ }^{* * *} 400 \mathrm{mg}$ ) when needed. Removal of the sutures and the periodontal dressings was done 1 week after the surgery, however after cleaning the site the dressing could be replaced if needed. Participants were recalled at 4 weeks interval for 6 months follow up period to evaluate the oral hygiene and for prophylaxis. Clinical and radiographic outcomes were recorded after 6 months from the surgery.

\section{Clinical Outcomes}

Clinical outcomes were measured immediately before surgery (baseline data) and 6 months after surgery. The clinical outcomes measured were plaque index (PI), gingival index (GI), PPD and CAL. Measurements were obtained using William's graduated periodontal probe to the nearest millimeter and parallel to the long axis of the tooth. Six sites per tooth were probed (the mesiobuccal, midbuccal, distoobuccal, mesiolingual, midlingual and distolingual). PI and GI were evaluated according to Silness and Löe in $1964{ }^{(19)}$ and Löe in $1967^{(20)}$ respectively. PPD was recorded from the crest of the gingival margin till the base of the periodontal pocket, and the CAL was measured from the cemento-enamel junction (CEJ) to the base of the periodontal pocket.

\section{Radiographic Outcome}

Radiographic outcome was measured immediately before surgery (baseline data) and 6 months after surgery. The radiographic outcome was the bone defect area (BDA). To assess the radiographic outcome, digital intraoral periapical radiographs were captured using the PSP plates combined with the Digora ${ }^{\circledR}$ system (21). For standardization, intraoral periapical parallel technique and film holders (XCP, RINN, United Kingdom) were used. PSP plate size 1 or 2 were used to capture the periapical radiographs: size 1 PSP plate was used for imaging the maxillary teeth and size 2 PSP plate was used for imaging the mandibular

E-mox 500 mg Cap., E.I.P.I.C.O., Egyptian Int. Pharmaceutical Industrial Co., A.R.E.

Flagyl: Metronidazole $250 \mathrm{mg}$. Tablets, Alexandria Pharmaceutical CO., Alexandria, Egypt.

Brufen, $400 \mathrm{mg}$ tablets, KAHIRA PHARM. CO. EGYPT. 
teeth. The radiographs were captured using digital dental X-Ray machine (SOREDEX Nahkelantie 160, F1-04301Tusula, Finland) set at $70 \mathrm{kVp}, 8$ $\mathrm{mA}$, and $0.04 \mathrm{sec}$. The PSP plate was scanned after radiograph taking using the SOREDEX DIGORA Optime digital intraoral scanner. Before conducting the linear measurements, calibration was performed to guarantee correct linear measurements. The digital built in ruler of the Digora for windows 2.5 Rev 1 Soredex software was used to measure the three lines bounding the triangle of the intraosseous bony defects. The three lines were: the $1^{\text {st }}$ line extended from the CEJ to the base of the intraosseous defect, the $2^{\text {nd }}$ line extended from the CEJ to the alveolar bone crest of the intra-osseous defect and the $3^{\text {rd }}$ line extended from the alveolar bone crest to the base of the intra-osseous defect. According to Singhal et al. in $2013^{(22)}$, the area of the triangular intra-osseous defect (BDA) was calculated using the geometric equation of triangle surface are $=1 / 2$ Base $\mathrm{x}$ Height. Two periapical radiographs were taken for each patient. The BDA was measured immediate before surgery and 6 months after surgery and the difference was calculated.

\section{Statistical Analysis}

Numerical data were explored for normality by checking the data distribution using KolmogorovSmirnov and Shapiro-Wilk tests. Data were represented as mean and standard deviation (SD). Mann-Whitney U test was used to compare between the two groups. Wilcoxon signed-rank test with Bonferroni's adjustment was used for pair-wise comparisons. The significance level was set at $\mathrm{P} \leq 0.05$ using a software statistical package for the statistical analysis (IBM SPSS Statistics Version 20 for Windows, New York, USA).

\section{RESULTS}

The two groups were matched at the base line for the clinical and the radiographic parameters (Table 1). In the PPG group, the mean PPD was $6.92 \pm 0.76$ $\mathrm{mm}$ and in the CM group was $6.82 \pm 1.1 \mathrm{~mm}$. As for the mean CAL, it was $6.42 \pm 0.56$ and $6.15 \pm 0.98$ in the PPG and the CM groups respectively. The mean BDA measured $8.367 \pm 4.13$ and $9.248 \pm 3.23$ $\mathrm{mm}^{2}$ in the two groups respectively. The mean PI scores for the PPG and CM group were $2.50 \pm 0.55$ and $2.01 \pm 0.46$ while the mean GI scores were 2.67 \pm 0.52 and $3 \pm 0$ respectively. The present results showed no significant difference between the two studied groups regarding all baseline clinical and radiographic outcomes $(\mathrm{P} \geq 0.05)$ (Table 1).

At 6 months, the two treatment modalities showed significant improvement in all clinical and radiographic outcomes when compared to the baseline at $\mathrm{P}<0.0001$. The mean PI and GI scores for the PPG group improved from $2.50 \pm 0.55$ to $0.50 \pm 0.53$ and from $2.67 \pm 0.52$ to $0.33 \pm 0.52$ respectively while the mean PI and GI scores for the CM group improved from $2.01 \pm 0.46$ to $0.62 \pm 0.25$ and from $3 \pm 0$ to $0.40 \pm 0.52$ respectively. The achieved improvement in the PD, CAL, BDA for the two treatments and the difference between the two treatments were non-significant (Table 2, 3).

PPD was reduced from $6.92 \pm 0.76 \mathrm{~mm}$ to 3.17 $\pm 0.65 \mathrm{~mm}$ in the PPG group. Similarly, in the CM group, PPD was decreased from $6.82 \pm 1.1 \mathrm{~mm}$ to $3.15 \pm 0.67 \mathrm{~mm}$ (Table 3 ). CAL showed improvement from $6.42 \pm 0.56 \mathrm{~mm}$ to $3.52 \pm 0.44 \mathrm{~mm}$ in the PPG group, and in the CM group CAL was improved from $6.15 \pm 0.98 \mathrm{~mm}$ to $3.6 \pm 0.57 \mathrm{~mm}$ (Table 3). BDA was reduced from $8.36 \pm 4.13 \mathrm{~mm}^{2}$ to $4.42 \pm 0.715 \mathrm{~mm}^{2}$ in the PPG group, and in the CM group, BDA was reduced from $9.24 \pm 3.23 \mathrm{~mm}^{2}$ to $5.7 \pm 2.99 \mathrm{~mm}^{2}$ (Table 3 ). 
TABLE (1): Clinical and radiographic outcomes (mean \pm SD) comparing both studied groups throughout the experimental period.

\begin{tabular}{|c|c|c|c|c|}
\hline Group & PPG & CM & Z-value & P-value \\
\hline $\begin{array}{c}\text { PPD Base Line } \\
\text { Mean } \pm \text { SD }\end{array}$ & $6.92 \pm 0.76 \mathrm{~mm}$ & $6.82 \pm 1.1 \mathrm{~mm}$ & -0.3314 & $0.7414^{*}$ \\
\hline $\begin{array}{c}\text { PPD 6 Months } \\
\text { Mean } \pm \text { SD }\end{array}$ & $3.17 \pm 0.65 \mathrm{~mm}$ & $3.15 \pm 0.67 \mathrm{~mm}$ & -0.0314 & $0.97606^{*}$ \\
\hline $\begin{array}{c}\text { CAL Base Line } \\
\text { Mean } \pm \text { SD }\end{array}$ & $6.42 \pm 0.56 \mathrm{~mm}$ & $6.15 \pm 0.98 \mathrm{~mm}$ & -0.3314 & $0.7414^{*}$ \\
\hline $\begin{array}{c}\text { CAL 6 Months } \\
\text { Mean } \pm \text { SD }\end{array}$ & $3.52 \pm 0.44 \mathrm{Mm}$ & $3.6 \pm 0.57 \mathrm{Mm}$ & -0.0314 & $0.97606^{*}$ \\
\hline $\begin{array}{c}\text { BDA Base Line } \\
\text { Mean } \pm \text { SD }\end{array}$ & $8.36 \pm 4.13 \mathrm{~mm}^{2}$ & $9.24 \pm 3.23 \mathrm{~mm}^{2}$ & -1.344 & $0.176^{*}$ \\
\hline $\begin{array}{c}\text { BDA 6 Months } \\
\text { Mean } \pm \text { SD }\end{array}$ & $4.42 \pm 0.715 \mathrm{~mm}^{2}$ & $5.7 \pm 2.99 \mathrm{~mm}^{2}$ & -1.8666 & $0.176^{*}$ \\
\hline
\end{tabular}

*Non-significant, $(P \geq 0.05)$

TABLE (2): Clinical and radiographic outcomes (mean \pm SD) comparing baseline and 6-months data in each studied group.

\begin{tabular}{|c|c|c|c|c|}
\hline Group & $\begin{array}{c}\text { PPD } \\
\text { Base Line } \\
\text { Mean } \pm \mathrm{SD} \\
\end{array}$ & $\begin{array}{c}\text { PPD } \\
6 \text { Months } \\
\text { Mean } \pm \text { SD } \\
\end{array}$ & Z-value & P-value \\
\hline $\begin{array}{c}\text { PPG } \\
\text { group }\end{array}$ & $6.92 \pm 0.76 \mathrm{~mm}$ & $3.17 \pm 0.65 \mathrm{~mm}$ & -3.9199 & $0.0001 *$ \\
\hline $\begin{array}{l}\text { CM } \\
\text { group }\end{array}$ & $6.82 \pm 1.1 \mathrm{~mm}$ & $3.15 \pm 0.67 \mathrm{~mm}$ & -3.9199 & $0.0001 *$ \\
\hline Group & $\begin{array}{c}\text { CAL } \\
\text { Base Line } \\
\text { Mean } \pm \text { SD }\end{array}$ & $\begin{array}{c}\text { CAL } \\
6 \text { Months } \\
\text { Mean } \pm \text { SD }\end{array}$ & $\mathrm{Z}$ - value & P-value \\
\hline $\begin{array}{l}\text { PPG } \\
\text { group }\end{array}$ & $6.42 \pm 0.56 \mathrm{~mm}$ & $3.52 \pm 0.44 \mathrm{~mm}$ & -3.9199 & $0.0001 *$ \\
\hline $\begin{array}{l}\text { CM } \\
\text { group }\end{array}$ & $6.15 \pm 0.98 \mathrm{~mm}$ & $3.6 \pm 0.57 \mathrm{~mm}$ & -3.9199 & $0.0001 *$ \\
\hline Group & $\begin{array}{c}\text { BDA } \\
\text { Base Line } \\
\text { Mean } \pm \text { SD }\end{array}$ & $\begin{array}{c}\text { BDA } \\
6 \text { Months } \\
\text { Mean } \pm \text { SD }\end{array}$ & $\mathrm{Z}$ - value & P-value \\
\hline $\begin{array}{l}\text { PPG } \\
\text { group }\end{array}$ & $8.367 \pm 4.13 \mathrm{~mm}^{2}$ & $4.42 \pm 0.715 \mathrm{~mm}^{2}$ & -3.9199 & $0.0001 *$ \\
\hline $\begin{array}{l}\text { CM } \\
\text { group }\end{array}$ & $9.248 \pm 3.23 \mathrm{~mm}^{2}$ & $5.7 \pm 2.99 \mathrm{~mm}^{2}$ & -3.9199 & $0.0001 *$ \\
\hline
\end{tabular}

* Significant $P<0.0001$. 
TABLE (3): Clinical and radiographic improvement (mean \pm SD) at 6 months after surgery for both studied groups.

\begin{tabular}{|c|c|c|c|c|}
\hline Group & $\begin{array}{c}\text { PPG } \\
\text { group }\end{array}$ & $\begin{array}{c}\text { CM } \\
\text { group }\end{array}$ & Z-value & P-value \\
\hline PPD reduction mm & $3.75 \pm 0.84$ & $3.68 \pm 1.17$ & 0.2521 & $0.8037^{*}$ \\
\hline \% PPD reduction & $53.89 \pm 9.81$ & $52.92 \pm 10.94$ & -0.5879 & $0.5552^{*}$ \\
\hline CAL gain Mm & $2.9 \pm 0.66$ & $2.55 \pm 0.76$ & 1.15 & $0.1393 *$ \\
\hline \% CAL gain & $44.84 \pm 7.51$ & $40.77 \pm 8.82$ & -0.5879 & $0.5552^{*}$ \\
\hline BDA Reduction $\mathbf{~ m m}^{2}$ & $3.94 \pm 4.09$ & $3.54 \pm 3.44$ & 1.26 & $1.33^{*}$ \\
\hline \% BDA Reduction & $39.47 \pm 20.77$ & $34.55 \pm 26.88$ & 0.9333 & $0.348^{*}$ \\
\hline
\end{tabular}

* Non-significant, $(P \geq 0.05)$

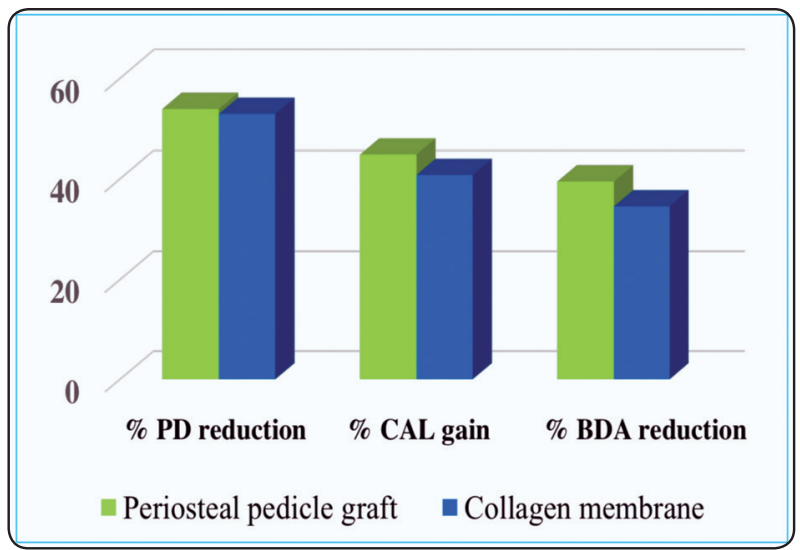

Fig. (1): mean \% change in PD, CAL and BDA in both groups.

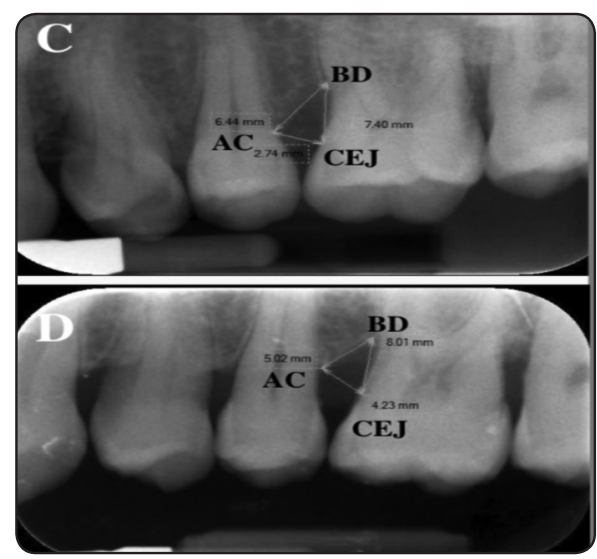

Fig. (3): periapical radiographs with linear measurements. (C) collagen group preoperative. (D) collagen group after 6 -months. $\mathrm{AC}=$ alveolar crest, $\mathrm{BD}=$ bottom of the defect, $\mathrm{CEJ}=$ cemento-enamel junction .

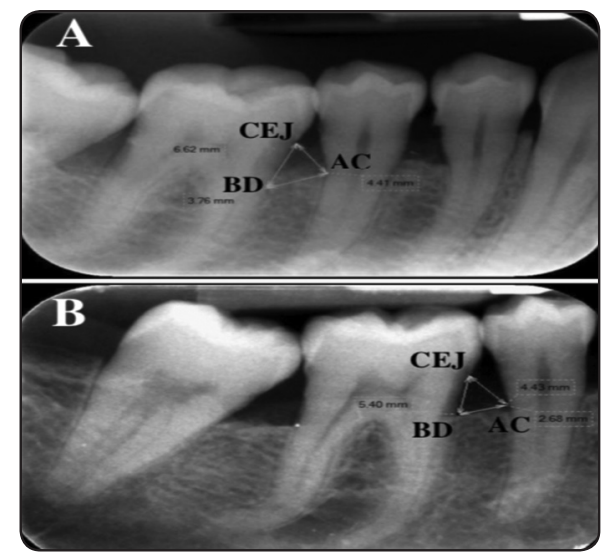

Fig. (2): periapical radiographs with linear measurements. (A) PPG group preoperative. (B) PPG group after 6-months. $\mathrm{AC}=$ alveolar crest, $\mathrm{BD}=$ bottom of the defect, $\mathrm{CEJ}=$ cemento-enamel junction.

\section{DISCUSSION}

For years periodontal regeneration has aimed to triple target new bone, new cementum and new periodontal ligament regeneration in between. Many strategies and protocols have been proposed including bone grafting, GTR, or the combination of both. The authors choice of using autogenous periosteal pedicle grafts was based on their biological compatibility, high vascularity, rich and diverse cellularity, acceptable rigidity, and strong regenerative capability ${ }^{(23,24)}$. All these merits raised the expectations of the autogenous PPG in comparison to the 
bioresorbable collagen membrane in the treatment of intra-osseous defects.

This clinical trial was designed on split-mouth basis to compare between the two treatment modalities in the same patient and under similar healing conditions. Several factors might dictate important influences on the outcome of the regenerative therapy, such as; patient's gender, age, oral hygiene, compliance to post-operative instructions and care, surgical manipulation and perfection, and defect characteristics and severity ${ }^{(25,26)}$. In a split-mouth design these factors have a similar influence on both therapeutic modalities to be compared ${ }^{(27,28)}$.

Intraosseous defects offer therapeutic challenges, which are not experienced with other periodontal defects. The morphology of an intrabony defect is difficult to access by non-surgical periodontal therapy alone. In addition to the complex anatomy of some defects, inadequate access offers difficulties in performing proper debridement. The width of the vertical defect is often insufficient to allow entry of an instrument to the base of the defect ${ }^{(29,30)}$. Based on the previous facts, this study focused on deepintraosseous defects characterized by probing pocket depth (PPD) and clinical attachment level (CAL) of ${ }^{3} 5 \mathrm{~mm}$. Moreover, Laurell et al. 1998 (31) stated that in order to benefit from regenerative procedures, the intrabony defect had to be at least $3 \mathrm{~mm}$ depth.

The benchmark for radiographic assessment of alveolar bone in periodontal treatment has been the digital intraoral radiography for the past 20 years. The proved accuracy of the digital linear measurement compared to the direct intraoperative linear measurement of osseous defect depth was established by Wolf et el. in $2001^{(21)}$. Therefore, digital intraoral radiography has been recommended by the Oral Radiology department - Cairo University as the imaging choice number one in periodontal assessment. Although available, CBCT was not advised as it has not been approved yet to be used as the standard radiographic imaging in periodontology until its dose limits, patients' safety and weight compared to another radiographic modality is clarified. Reliance on simple linear measurement of intra-osseous defects has been and still the major milestone to radiographically assess the defect depth ${ }^{(21)}$. Defect depth measurement provides an insight about the attachment level loss or gain vertically along the root surface. However, it doesn't give a true clue about the amount of bone fill within the intra-osseous defect or consider the width of the bone defects horizontally. Therefore, radiographic assessment measuring the bone defect area (BDA) was used over simple linear measurement to evaluate the actual bone fill of the intra-osseous defect ${ }^{(22)}$.

Different studies have used the periosteum in GTR as a treatment for gingival recession ${ }^{(32)}$, furcation involvement ${ }^{(33)}$ and osseous defects ${ }^{(13,22)}$, and showed promising clinical results regarding PPD and CAL. However, limited studies held comparison between the periosteum and collagen as a membrane in the treatment of intra-osseous defects ${ }^{(34,35)}$.

The results of this study revealed statistically significant improvement in CAL, PPD, and BDA in both the CM and the PPG groups. However, no statistically significant difference was found between both the bioresorbable $\mathrm{CM}$ and the autogenous PPG regarding the clinical and the radiographic outcomes studied.

The results of this study went in agreement with that of Moghaddas et al. (2010) ${ }^{(34)}$, which compared the efficacy of palatal tissue graft and collagen barrier membrane with Bio-Oss in the treatment of intrabony defects. Their results showed that there were statistically significant improvements in the two treatments, but there were no statistically significant differences in any of the variables between both groups. The clinical attachment gain in their study were $1.5 \mathrm{~mm}$ and $1.9 \mathrm{~mm}$ and the pocket depth reduction were $2.6 \pm 1.7 \mathrm{~mm}$ and $3.2 \pm 1.9 \mathrm{~mm}$ in 
the palatal connective tissue and collagen groups respectively. Their results were less than those in our studies probably because of the different methodology, operator skill, the equipment used and the follow up interval. The amount of bone fill in the palatal connective tissue and collagen group in their study was $3.4 \mathrm{~mm}$ and $3.9 \mathrm{~mm}$ respectively and was measured using simple linear measurements with periodontal probe on surgical re-entry.

Barrier membrane used in GTR generally creates a stopper, which delays the apical migration of the epithelial attachments and thus preserves the vacancy of the osseous defect to be repopulated by the undifferentiated progenitor cells. This helps in truly regenerating both the cellular and the fibrous component of the intra-osseous defect and this was reflected on the results of this study. Clinical and histological studies using absorbable collagen membranes have shown them to be effective in treating periodontal defects ${ }^{(36,37,38)}$. In addition, the collagen membrane was especially selected in this study owing to being chemotactic to fibroblasts ${ }^{(39)}$, it provides a scaffold for periodontal ligament cell migration ${ }^{(40)}$, it is a weak immunogen ${ }^{(41)}$, it can be easily manipulated and adapted ${ }^{(42)}$ and it does not require a second stage surgery to be removed ${ }^{(43)}$. In addition, other clinical investigations utilized autogenous periosteal barrier membrane according to several clinical benefits. The biological coverage was obtained from a site contiguous to the defect; so a second connective tissue graft donor site was not required. Moreover, the use of autogenous tissue prevented the occurrence of adverse reactions and expenses were reduced since biomaterials were not utilized ${ }^{(44)}$. Furthermore, the physiologic mode of growth factor delivery that could be achieved with periosteal osteoprogenitor cells could offer a great advantage of using the periosteum in periodontal regenerative therapy ${ }^{(45,46)}$.

In agreement with this study, Paolantonio et al. (2010) ${ }^{(35)}$ results showed statistically significant improvement in the clinical parameters from the baseline till 1 year postoperatively when compared collagen membranes and autogenous periosteal membranes for GTR in the treatment of intraosseous defects. The collagen group and periosteal membrane group showed $3.2 \mathrm{~mm}$ and $3.9 \mathrm{~mm}$ CAL gain respectively without significant difference between both treatments. Although they used autogenous bone chips combined with the periosteal membrane, yet their results were still comparable to the results of this study. This might question the additional benefit of bone grafts with GTR membranes.

PPG in our study showed mean PPD reduction of $4.13 \pm 0.81 \mathrm{~mm}$, CAL gain of $3.8 \pm 0.75 \mathrm{~mm}$, and BDA reduction of $3.94 \pm 4.09 \mathrm{~mm}^{2}$. The clinical improvements in PPD reduction and CAL gain in this study were comparable to the results obtained by Gamal et al. in $201{ }^{(14)}$ who evaluated MPP graft as a biologic GTR membrane in the treatment of intrabony defects and showed $3.8 \mathrm{~mm}$ PPD reduction and $3.4 \mathrm{~mm}$ CAL gain. It was suggested by the authors that placement of a vascularized MPP graft as a barrier membrane significantly improved clinical parameters of deep intra-bony defects. They assessed the bone fill twice: clinically during surgery and radiographically immediate postoperative from conventional parallel periapical radiographs to record base line data. They repeated the same linear measurements during surgical reentries and from the radiographs at 3,6,9 months postoperative. The mean difference in the bone file from the time of surgery till 9 months after surgery was statistically significant $3.2 \mathrm{~mm}$ compared to $3.94 \mathrm{~mm}^{2}$ in our study. However, their radiographs were film-based, taken with standard exposure parameters of 0.8 second, processed chemically and were digitized using digital CCD-video camera. It is important to remember that standard exposure time could occasionally cause burnout of alveolar crest and hence lead to inaccurate linear measurements. In addition, they didn't mention how the chemical 
processing was standardized to guarantee proper image contrast. Faulty chemical processing could cause burnout of alveolar crest as well and nondiagnostic image contrast. Moreover, digitization of radiographs is another step that leads to loss of image details. In addition, they radiographically assessed the bone fill by simple linear measurements not by bone area calculation.

On the contrary, Amicarelli and Alonso $1999^{(44)}$ succeeded to reach $3 \mathrm{~mm}$ PPD reduction and a $2 \mathrm{~mm}$ decrease in the furcation depth measurement after 6 months using autogenous periosteum as a barrier membrane in treating class II furcation defect. Although they used a technique that was similar to the one used in this study, yet their findings were far less than the findings obtained by this investigation regarding the PPD reduction. This may be related to differences in defects morphology (furcations) and follow up periods.

Further contrast was found in Sighal et al.

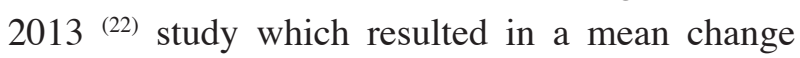
in PD and CAL of $2.33 \pm 1.03$ and $1.83 \pm 0.75$ $\mathrm{mm}$, respectively when they used PPG in treating 2 wall bone defects. Their mean BDA percentage reduction was $14.08 \% \pm 12.97 \%$. The superior results of our study could be justified by the mean defect depth which was $1 \mathrm{~mm}$ less at the base line in this study, the defect morphology namely the osseous walls remaining and the defect width, the different imaging receptor (PSP over the Schick Technologies), digital system and software used (Digora ${ }^{\circledR}$ system over Radio-visiographs) and the time of radiograph taking to record the base line data (immediate before surgery over recording the base line data during initial examination).

Moreover, the study by Saimbi et al, $2014{ }^{(47)}$ showed less results than this study when they used periosteum as a barrier membrane in treating intrabony defects. Their gain in CAL was 2.00 $\pm 0.26 \mathrm{~mm}$, the decrease in PPD was $3.90 \pm 0.35$ $\mathrm{mm}$ and the bone defect fill was $1.40 \pm 0.16 \mathrm{~mm}$.
Unfortunately, their study didn't include any inclusion or exclusion criteria, didn't mention the type of the intra osseous defect and their use of CT dentascan for radiographic assessment was not justified.

Bone grafting although commonly used and although it was proved to contribute in wound stability and succeeded to improve PPD and CAL, however, it was not used in this study as it failed to restore a full periodontal unit in other studies ${ }^{(48,49)}$. Moreover, conflicting results have been reported to date on the effectiveness of combination procedures compared to others using barrier membranes alone ${ }^{(50)}$. The study conducted by Kumar et el. in $2014^{(50)}$ compared the PPG alone to PPG combined with alloplastic material and measured the linear distance from the cemento-enamel junction to the base of bone defect (CEJ-BBD) using Radio Visio Graphy (RVG) digital system and Schick technology software. Their results showed statistically significant lower mean defect fill when combined PPG and bone graft was used compared to the PPG alone.

In this clinical study, collagen membrane showed PPD reduction and CAL gain $3.73 \pm 0.75$ $\mathrm{mm}$ and $3.70 \pm 0.68 \mathrm{~mm}$ respectively 6 months after surgery. Our results were supported by Mattson et al. (1995) ${ }^{(42)}$, who tested the ability of collagen membranes to promote regeneration in periodontal intrabony defects. The mean PPD reduction in their study ranged from 3.1 to $5.5 \mathrm{~mm}$ in collagen-treated groups.

The meta-analysis conducted by Evans et al. $1997{ }^{(51)}$ analyzed GTR articles published between 1994 to early 1996 and reported that the mean PPD reduction was $4.1 \mathrm{~mm}$ and the mean CAL gain was $4.0 \mathrm{~mm}$ with collagen membranes. The results of this study were highly similar to their meta-analysis, which highlights the ongoing fact that collagen membrane is an efficient GTR barrier. Further support was gained from the results of Kothiwale (2014) ${ }^{(52)}$ who recorded $5.1 \mathrm{~mm}$ PPD reduction, 
5.0 $\mathrm{mm}$ CAL gain and $1.2 \mathrm{~mm}$ bone gain when they used chorionic collagen membrane in the treatment of intra-bony defects. Their higher clinical results could be due to the longer follow up interval and the unique features of chorionic membranes. Their bone gain assessed radiographically was based on simple linear measurements; they used CMOS sensor, RVG digital system and software to capture the standardized parallel periapical radiographs. On the other hand, the systematic review conducted by Parrish et al. (2009) ${ }^{(49)}$ reported an average mean CAL gain of $2.44 \mathrm{~mm}$ and an average PPD reduction of $2.53 \mathrm{~mm}$, when collagen barriers were used for treatment of interproximal defects. Their results were inferior to the results of this study, which could be attributed to the fact that only four data sets were found, which used collagen without graft material and could match their selection criteria. Moreover, the results of this study were higher than those reported in a systematic review by Murphy and Gunsolley (2003) ${ }^{(53)}$. They reported $0.95 \mathrm{~mm}$ improvement in the CAL after the application of collagen membrane in treating intrabony defects, which was not significant from the baseline measurements. However, this could be explained by the exclusion of several studies that didn't match the inclusion criteria of their systematic review for which their results were based on four studies only.

\section{CONCLUSIONS}

It could be concluded from this study within its limitations that both treatment modalities could improve the clinical and radiographic outcomes and were effective in management of intrabony defects.

\section{REFERENCES}

1. Pihlstrom B L, McHugh R B, Oliphant T H, Ortiz-Campos C. Comparison of surgical and nonsurgical treatment of periodontal dis- ease. A review of current studies and additional results after 61/2 years. J Clin Periodontol 1983; 10: 524-541.

2. Kaldahl W B, Kalkwarf K L, Kashinath D, Patil D, Molvar M P and Dyer J K. Long-term evaluation of periodontal therapy: I. Response to 4 therapeutic modalities. J Periodontol 1996; 67: 93-102.

3. Caton J, Nyman S and Zander H. Histometric evaluation of periodontal surgery. II. Connective tissue attachment levels after four regenerative procedures. J Clin Periodontol 1980; 7: 224-231

4. Isidor F, Attström R and Karring T. Regeneration of alveolar bone following surgical and non-surgical periodontal treatment. J Clin Periodontol 1985; 12: 687-696.

5. Stahl SS, Froum SJ and Kushner L. Periodontal healing following open flap debridement procedures. II. Histologic observations. J Periodontol 1982; 53: 15-21.

6. Froum S J, Coran M, Thaller B, Kushner L, Scopp I W, Stahl S S. Periodontal healing following open debridement procedures. I. Clinical assessment of soft tissue and osseous repair. J Periodontol 1982; 53: 8-14.

7. The American Academy of Periodontology. Glossary of Periodontal Terms, 4th edition. Chicago, IL: American Academy of Periodontology, 2001.

8. Melcher A H. On the repair potential of periodontal tissues J Periodontol 1976; 47: 256-260.

9. Gottlow J, Nyman S, Karring $\mathrm{T}$ and Lindhe J. New attachment formation as the result of controlled tissue regeneration. J Clin Periodontol 1984; 11: 494-503.

10. Gottlow J, Nyman S, Lindhe J, Karring T and Wennström J. New attachment formation in the human periodontium by guided tissue regeneration. Case reports. J Clin Periodontol 1986; 13: 604-616.

11. Mellonig J T, Seamons B C, Gray J L and Towle H J. Clinical evaluation of guided tissue regeneration in the treatment of grade II molar furcation invasions. Int $\mathrm{J}$ Periodontics Restorative Dent 1994; 14: 254-271.

12. Cortellini $\mathrm{P}$ and Tonetti M S. Focus on intrabony defects: Guided tissue regeneration. Periodontol 2000 2000; 22: 104-132.

13. Gamal AY and Mailhot J M. A novel marginal periosteal pedicle flap as an autogenous guided tissue membrane for the treatment of intrabony periodontal defects. Journal of the International Academy of Periodontology 2008; 10:106-117.

14. Gamal A Y, Attia-Zouair M G, El Shall O S, Khedr M M F, El-farag M A and Mailhot J M. Clinical Re-entry and Histologic Evaluation of Periodontal Intrabony Defects 
Following the Use of Marginal Periosteal Pedicle Graft as an Autogenous Guided Tissue Membrane. Journal of the International Academy of Periodontology 2010; 12/0: $1-14$.

15. Ishida $H$, Tamai $S$, Yajima $H$, Inoue $K$, Ohgushi $H$ and Dohi Y. Histologic and biochemical analysis of osteogenic capacity of vascularized periostium. Plastic and Reconstructive Surgery 1996; 79: 512-518.

16. Ueno T, Kagawa $\mathrm{T}$ and Ishida $\mathrm{N}$ et al. Prefabricated bone graft induced from grafted periosteum for the repair of jaw defects: an experimental study in rabbits. Journal of Craniomaxillofacial Surgery 2001; 29:219-223.

17. Haney J M, Nilveus $R$ E, McMillan $P$ J and Wikesjo U M. Periodontal repair in dogs: expanded polytetrafluoroethylene barrier membranes support wound stabilization and enhance bone regeneration. J Periodontol 1993; 64: 883-890.

18. Abramson J H. The Cornell Medical Index as an epidemiological tool. Am. J Public Health 1966; 56: 278.

19. Silness $\mathbf{J}$ and Löe H. Periodontal disease in pregnancy. II. Correlation between oral hygiene and periodontal condition. Acta Odontol Scand 1964; 22: 121-135.

20. Löe H. The gingival index, the plaque index and the retention index system. J Periodontol 1967; 38: 610-616.

21. Wolf B, von Bethlenfalvy E, Hassfeld S, Staehle HJ, Eickholz P. Reliability of assessing interproximal bone loss by digital radiography: Intrabony defects. J Clin Periodontol 2001; 28:869-78.

22. Singhal R, Nandlal, Kumar A, Rastogi P. Role of space provision in regeneration of localized two-wall intrabony defects using periosteal pedicle graft as an autogenous guided tissue membrane. J Periodontol 2013;84:316-24.

23. Bouchard P, Malet J, Borghetti A. Decision-making in aesthetics: Root coverage revisited. Periodontol 2000 2001;27:97-120.

24. De Bari C, Dell'Accio F, Vanlauwe J, Eyckmans J, Khan IM, Archer CW, et al. Mesenchymal multipotency of adult human periosteal cells demonstrated by single-cell lineage analysis. Arthritis Rheum 2006;54:1209-21.

25. Cortellini P, Pini-Prato G and Tonetti M S. Periodontal regeneration of human infrabony defects. V. Effects of oral hygiene on long-term stability. J Clin Periodontol 1994; 21: 606-610.
26. Cortellini P and Bowers G M. Periodontal regeneration of intrabony defects: An evidence-based treatment approach. Int. J Periodont Rest Dent 1995; 15: 128-145.

27. Pontoriero R, Lindhe J, Nyman S, Karring T, Rosenberg E and Sanavi F. Guided tissue regeneration in degree II furcation-involved mandibular molars. A clinical study. J Clin Periodontol 1988; 15: 247-254.

28. Eickholz P, Kim T S and Holle R. Regenerative periodontal surgery with non-bioabsorbable and biodegradable barriers: Results after 24 months. J Clin Periodontol 1998; 25: 666-676.

29. Guillemin M R, Mellonig J T and Brunsvold M A. Healing in periodontal defects treated by decalcified freeze-dried bone allografts in combination with ePTFE membranes. I. Clinical and scanning electron microscope analysis. J Clin Periodontol 1993; 20: 528-536.

30. Chen C C, Wang H L, Smith F, Glickman G N, Shyr Y, O'Neal R B. Evaluation of a collagen membrane with and without bone grafts in treating periodontal intrabony defects. J Periodontol 1995; 66: 838-847.

31. Laurell L, Gottlow J, Zybutz M and Perrson R. Treatment of intrabony defects by different surgical procedures. A Literature review. J Periodontol 1998; 69: 303-313.

32. Mahajan A. Treatment of multiple gingival recession defects using periosteal pedicle graft: A case series. J Periodontol 2010;81:1426-31.

33. Lekovic V, Kenney EB, Carranza FA, Martignoni M. The use of autogenous periosteal grafts as barriers for the treatment of class-II furcation involvements in lower molars. J Periodontol 1991;62:775-80.

34. Moghaddas H, Soltani L, Moghaddas O. Efficacy of Palatal Connective Tissue Graft as a Membrane in the Treatment of Intrabony Defects. Journal of Periodontology \& Implant Dentistry, 2010; 2(2):70-76. The article is available from: http://dentistry.tbzmed.ac.ir/jpid

35. Paolantonio M, Femminella B, Coppolino E, Sammartino G, D'Arcangelo C, Perfetti G. et al. Autogenous periosteal barrier membranes and bone grafts in the treatment of periodontal intrabony defects of single-rooted teeth: a 12-month reentry randomized controlled clinical trial. J Periodontol. 2010;81:1587-95.

36. Chung K M, Salkin L M, Stein M D and Freedman A L. Clinical evaluation of a biodegradable collagen membrane in guided tissue regeneration. J Periodontol 1990; 61:732-736. 
37. Wang H, O'Neal R, Thomas C, Shyr Y and MacNeil R. Evaluation of an absorbable collagen membrane in treating Class II furcation defects. Journal of Periodontology 1994; 65: 1029-1036.

38. Parodi R, Carusi G, Santarelli G, Nanni F, Pingitore R and Brunel G. Guided tissue regeneration employing a collagen membrane in a human periodontal bone defect: a histologic evaluation. Int J Periodontics Restorative Dent 1997; 17: 282-291.

39. Yaffe A, Ehrlich J and Shoshan S. Restoration of periodontal attachment employing enriched collagen solution in the dog. Journal of Periodontology 1984; 55: 623-8.

40. Quteish D, Singrao S and Dolby A E. Light and electron microscopic evaluation of biocompatibility, resorption and penetration characteristics of human collagen graft material. J Clin Periodontol 1991; 18: 305-311.

41. Quteish D and Dolby AE. The use of irradiated cross-linked human collagen membrane in guided tissue regeneration. $\mathrm{J}$ Clin Periodontol 1992; 19: 476-484.

42. Mattson J S, Gallagher S J and Jabro M H. The use of 2 bioabsorbable barrier membranes in the treatment of interproximal intrabony periodontal defects. J Periodontol 1999; 70: 510-517.

43. Tatakis N, Promsudthi A and Wikesjö ME. Devices for periodontal regeneration. Periodontol 2000 1999; 19:59-73

44. Amicarelli R G and Alonso C A. Treatment of class II furcation lesions using an autogenous periosteal barrier. Pract Periodont Aesthet Dent 1999; 11(2): 237-244.

45. Yu X, Hsieh SC, Bao W and Graves DT. Temporal expression of PDGF receptors and PDGF regulatory effects on osteoblastic cells in mineralizing cultures. Am J Physiol 1997; 272: C1709-C1716.
46. Marzouk K M, Gamal A Y, Al-Awady A A, Sharawy M M. Osteoconductive effects of vinyl styrene microbeads in rat calvarial defects. J Oral Maxillofac Surg 2007; 5:1508-1516.

47. Saimbi CS, Gautam A, Khan MA, Nandlal. Periosteum as a barrier membrane in the treatment of intrabony defect: A new technique. J Indian Soc Periodontol 2014;18:3315. Available at www.jisponline.com. DOI:10.4103/0972124X.134571

48. Polimeni G, Xiropaidis AV, Wikesjö UM. Biology and principles of periodontal wound healing/regeneration. Periodontol 2000 2006;41:30-47.

49. Parrish LC, Miyamoto T, Fong N, Mattson JS,Cerutis DR. Non-bioabsorbable vs. bioabsorbable membrane: assessment of their clinical efficacy in guided tissue regeneration technique. A systematic review. J Oral Sci 2009; 51: 383-400.

50. Kumar A, Lal N, Singhal R, Rastogi P. Comparative evaluation of periosteum as a barrier membrane with and without an alloplastic bone graft in periodontal osseous defects: A 9 months follow-up study. J Indian Soc Periodontol 2014;18:493-6. Available from: http://www. jisponline.com/text.asp?2014/18/4/493/138706

51. Evans GH, Yukna RA, Cambre KM, Gardiner DL. Clinical regeneration with guided tissue barriers. Curr Opin Periodontology 1997; 4: 74-81.

52. Kothiwale, SV. The evaluation of chorionic membrane in guided tissue regeneration for periodontal pocket therapy: a clinical and radiographic study. Cell and Tissue Banking, 2014; 15 (1): 145-152.

53. Murphy KG, Gunsolley JC. Guided tissue regeneration for the treatment of periodontal intrabony and furcation defects. A systematic review. Ann Periodontol 2003; 8: 266-302. 